\title{
El campo de las revistas políticas bajo el franquismo
}

\author{
Joan Pecourt \\ $\mathrm{PhD}$ in Social and Political Sciences \\ University of Cambridge \\ juanpec@cantab.net
}

\section{Resumen}

En este artículo se pretende identificar un espacio social que se originó en los años del franquismo y al cual denomino campo de las revistas politicas. Analizaremos las condiciones sociales que hicieron posible el desarrollo de este espacio, incidiendo especialmente en el reemplazo de las generaciones intelectuales y en el desarrollo del mercado cultural. Como veremos, el campo de las revistas políticas proporcionó a los intelectuales del anti-franquismo cierta autonomía frente al poder político aunque también les impuso determinadas limitaciones. Así, en su interior, el abanico de los discursos posibles dependió, no sólo de la censura ejercida sobre la voluntad individual por las autoridades franquistas, sino también de las reglas de juego impuestas por el propio campo cultural.

Palabras clave: intelectuales, poder político, poder intelectual, campo cultural, espacio político.

\section{Abstract. The field of political journals under Francoism}

In this article, I shall identify a social space originated during the Francoist years. I shall refer to this region as the field of political journals. I shall analyse the social conditions that made the development of this sphere possible, especially referring to the replacement of intelectual generations and the development of the market for cultural products. As I shall show, the field of political journals provided anti-Francoist intellectuals with some degree of autonomy against political power, althougth it also imposed its own limitations and forms of censorship. In this sense, in this region, the range of theoretical and political positions depended, not only on the political censorship imposed over the individual will, but also on the rules of the game imposed by the cultural field itself.

Key words: intellectuals, political power, intellectual power, cultural field, political space.

\section{Sumario}

La cultura del franquismo y el debate sobre "el problema de España»

Los indicios de crisis en la cultura del franquismo

La rebelión de los intelectuales jóvenes

El mercado y la búsqueda de la autonomía
Las condiciones políticas y económicas del diálogo

La revolución política y la seducción de la cultura de masas

Sobre los usos más adecuados del poder intelectual

Bibliografía 
En los últimos años, existe un interés renovado por el universo simbólico del franquismo y por los orígenes más ocultos, situados en algún punto intermedio entre el heroísmo y la complacencia, de la disidencia intelectual que facilitó el camino hacia la democracia. Estas incursiones en el pasado reciente, realizadas sobre todo desde el análisis histórico, se han preocupado por la retórica de los discursos intelectuales del periodo, por las implicaciones políticas de las palabras y de las imágenes. El historiador Jordi Gracia, por ejemplo, describe la resistencia silenciosa del lenguaje pausado y reflexivo heredero de la ilustración frente al lenguaje exaltado e irracional de los falangistas en los primeros años del franquismo ${ }^{1}$. Santos Juliá, por su parte, analiza la evolución de los discursos intelectuales desde el liberalismo decimonónico, recogiendo metáforas e imágenes recurrentes, y certifica la paulatina desaparición de las grandes metanarrativas en torno a la nación española en favor de un lenguaje en democracia ${ }^{2}$. Estos autores, sin embargo, tienden a dejar de lado las condiciones sociales (o más bien podríamos decir estructurales) que posibilitaron la elaboración y difusión de estas narrativas, conceptos y metáforas. La creación de un sistema de pensamiento con un cierto grado de eficacia exige algo más que la participación de una voluntad individual o la existencia de un cierto estado de ánimo colectivo; requiere también la aparición de determinadas estructuras sociales y, utilizando un concepto que puede resultar incómodo en el ámbito de la creación y la imaginación, el apoyo de poderes culturales específicos que sustenten las ideas que se pretenden difundir en el espacio público. La fuerza del discurso, el poder de la palabra, depende tanto de la calidad y originalidad de los conceptos y las metáforas presentadas como de su cercanía a determinados poderes políticos, económicos, eclesiásticos o estrictamente culturales.

Siguiendo esta premisa, en las páginas siguientes pretendo esbozar la aparición de un espacio cultural durante el franquismo en donde se dieron las condiciones estructurales básicas para que surgieran los movimientos intelectuales de oposición al franquismo. A esta región la denominaremos campo de las revistas políticas. El concepto de campo está tomado de Pierre Bourdieu y define la existencia de un universo social relativamente autónomo, caracterizado por una lógica de funcionamiento propia y una forma de poder específica, distinguiéndose así de los demás campos que componen la sociedad ${ }^{3}$. Veremos cómo el campo de las revistas políticas, generado bajo las condiciones impuestas por el franquismo, se distinguió de otros campos culturales de la época, y en especial de los medios de comunicación de masas, que se mantenían dentro de la ortodoxia nacionalcatólica sin ofrecer ninguna alternativa política o social al régimen existente. En contraste con ellos, el campo de las revistas políticas se caracterizó desde sus orígenes por oponer cierta resistencia simbólica a la dictadura franquista, con intensidad variable dependiendo del momento histórico.

2. Juliá (2004, p. 461-2).

3. Bourdieu y Wacquant (1992, p. 94-115). 
¿Cuáles fueron las condiciones sociales que dieron lugar a la aparición del campo de las revistas políticas? ¿Cómo se originó un poder propiamente intelectual dentro de este espacio? ¿Cuál fue la lógica interna y los límites de dicho universo diferenciado? Éstas son algunas de las preguntas a las que me gustaría responder en este artículo. Mediante la selección de algunos ejemplos relevantes, intentaré mostrar las líneas maestras que definieron la aparición y el desarrollo de este microcosmos social bajo la dictadura de Franco.

\section{La cultura del franquismo y el debate sobre «el problema de España»}

Como ya sabemos, la cultura del primer franquismo estaba dominada por la competición entre dos facciones de la inteligencia alineada con los vencedores de la guerra civil: los católicos y los falangistas ${ }^{4}$. El choque entre el falangismo y el catolicismo no era un asunto aislado del mundo cultural; al contrario, estaba íntimamente ligado a las tensiones internas que durante aquellos años estructuraban el campo político franquista. En el ámbito de la ciencia, la acumulación de poder político facilitaba el acceso a las posiciones dominantes en diferentes plataformas institucionales (educación básica, formación universitaria, centros de investigación, editoriales). Con el paso del tiempo, la relación de fuerzas entre ambos grupos fue inclinándose poco a poco hacia el polo católico ${ }^{5}$. Los falangistas fueron progresivamente cesados de sus responsabilidades gestoras en la "fortaleza franquista» —el núcleo donde se tomaban las decisiones políticas - y en los distintos campos culturales. Esta realidad dividió al grupo falangista en dos sectores: los mas persistentes siguieron fieles al credo falangista e intentaron defender los restos de su poder dentro del entramado social franquista, mientras que los inconformistas emprendieron una lenta evolución hacia el liberalismo y la crítica del régimen ${ }^{6}$. Éstos últimos, denominados «falangistas liberales» por algunos autores, abrieron las primeras brechas en el cerrado y uniforme universo del franquismo, al que José Ortega y Gasset había definido muy apropiadamente como «el tibetanismo español»?

Los primeros vestigios de un poder propiamente intelectual, es decir, un poder originado en el mundo de la cultura e independiente de los poderes políticos y eclesiásticos establecidos, pudieron vislumbrarse en espacios culturales muy especializados, y alcanzaron visibilidad pública tan sólo de manera intermitente y efímera. Estas primeras corrientes de disidencia intelectual se encontraban, por tanto, muy alejadas de unos medios de comunicación de masas

4. Fusi (1999, p. 100-7).

5. El punto de inflexión se encuentra en la caída ministerial de Ramón Serrano Suñer en 1942, el gran defensor y representante del grupo de Ridruejo y Laín dentro de la fortaleza franquista. Los grupos conservadores tomaron el control que estos intelectuales habían ejercido sobre la Delegación de Prensa y Propaganda (Díaz, 1983, p. 33).

6. Mangini (1987, p. 36).

7. Existe toda una polémica en torno al concepto del "falangismo liberal», pero en este artículo no nos interesa entrar en ella. Para ver una de sus expresiones más recientes, consultar Juliá (2004, p. 334). 
férreamente controlados por las fuerzas (políticas, económicas y eclesiásticas) más significativas del régimen. La censura, al servicio de estos poderes, actuaba como filtro selectivo que distorsionaba y restringía gravemente la forma y el contenido de los mensajes que se podían difundir en el espacio público ${ }^{8}$. Para contrarrestar los efectos perversos de la censura, la protesta debía realizarse mediante una manipulación hábil y estratégica de los conceptos políticos básicos que legitimaban al régimen, evitando referencias directas y explotando el carácter connotativo del lenguaje. Esta subversión conceptual era más factible realizarla mediante disquisiciones teóricas alejadas de su contexto social, porque era la única manera de revelar situaciones que no se podían nombrar y menos criticar de forma directa. Por ello, aunque en muchas ocasiones el idealismo y la abstracción de los problemas teóricos discutidos se podrían interpretar como formas intolerables de entretenimiento intelectual o como un mero escapismo de las élites educadas frente a las condiciones paupérrimas de la España de la postguerra, en realidad éstos trataban de dar sentido a los diferentes poderes que operaban en los campos culturales de la sociedad española.

Las primeras colisiones entre diferentes poderes culturales, definidos por su relación de privilegio o de autonomía respecto al poder político, se evidenciaron en la polémica sobre el "problema de España» entre el falangista Pedro Laín Entralgo, cofundador de la revista Escorial, considerada por muchos uno de los núcleos iniciales de la disidencia intelectual, y el católico Rafael Calvo Serer, uno de los principales teóricos de la revista integrista Arbor y asociado al Opus Dei ${ }^{9}$. Laín, después de pasar varios años estudiando la cultura española del siglo XIX, en 1949 publicó una recopilación de artículos titulada España como problema. En ella, Laín analizaba su experiencia personal y también la de su generación, los que más tarde serían llamados "la generación de 1936». Él se consideraba parte de una generación «espiritualmente ensangrentada y astillada", la formada por aquéllos que se vieron envueltos en una guerra civil durante los años de formación y tuvieron que enfrentarse a la dramática opción de escoger entre dos visiones del mundo incompatibles ${ }^{10}$. Aunque Laín tomó partido por los vencedores, por la retórica católica y nacional, en su libro insistía en la necesidad de entender e integrar las tradiciones culturales derrotadas, ya que éstas también formaban parte del «ser español». Pretendía completar, así, una síntesis definitiva de las filosofías hispánicas resucitando la historia completa del pensamiento del país, algo que había resultado imposible antes de

8. Para que un texto pudiera publicarse, pasaba por un censor que debía responder a seis preguntas: ¿ataca al Dogma? ¿a la Iglesia? ¡a sus miembros? ¿a la moral? ¡ataca al régimen y sus instituciones? ¡a las personas que colaboran o han colaborado con el régimen? (Morán, 1998, p. 275).

9. En estos momentos, los católicos asociados al emergente Opus Dei y a otras organizaciones religiosas controlan las difentes esferas de la cultura frente a la progresiva debilidad institucional del grupo surgido en torno a la revista Escorial. Los sucesores del falangista Serrano Suñer en el Ministerio de Cultura, Pedro Sainz Rodríguez y José Ibáñez Martín, se inclinarán claramente por la colaboración estrecha con los católicos más conservadores.

10. Díaz (1983, p. 52). 
la guerra. Esta síntesis, sin embargo, no parece que fuera a producirse en condiciones de igualdad, sino que se trataba, más bien, de una asimilación selectiva de la cultura de los vencidos por parte de los vencedores ${ }^{11}$.

La tesis de la reconciliación de Laín se encontró inmediatamente con la réplica de Calvo Serer en su libro España sin problema, donde defendía la unidad alcanzada en 1939 y la eliminación de todas las discrepancias existentes entre los españoles. No es posible, argumentaba Calvo Serer contradiciendo a Laín, introducir elementos extraños e incompatibles con la tradición nacional ortodoxa. Esta interpretación del «ser español», apoyada por los sectores reaccionarios de la tradición antiliberal, rechazaba todos los logros culturales de la era moderna o, al menos, la compatibilidad de estos logros con la identidad nacional. El catolicismo era entendido como un modelo de ortodoxia; una filosofía perenne (situada por encima de las modas intelectuales y las revoluciones cientificas) que proporcionaba una explicación completa del mundo material y espiritual y que, por tanto, no necesitaba ningún tipo de suplemento filosófico foráneo. Si para Laín, el ser español era un problema y su solución requería la participación de todas las tradiciones culturales y voces disidentes (aunque convenientemente adaptadas a las condiciones del franquismo), para Calvo Serer, por el contrario, el problema español se había solucionado con la eliminación de las aberraciones liberales y comunistas.

Lo interesante de este debate es observar cómo, por debajo del lenguaje heideggeriano de los contendientes, la discusión estaba sacando a la superficie la relación problemática entre el campo político y los campos culturales en el primer franquismo. La defensa de la ortodoxia y el control absoluto de las opiniones heterodoxas que proponía Calvo Serer puede ser entendido como una defensa de la unificación de los discursos intelectuales generados en los diferentes campos culturales, siguiendo las líneas maestras establecidas por los poderes políticos y eclesiásticos. Laín, por su parte, defendía la necesidad de interpretar las diferentes tradiciones culturales, y con ello rechazaba la legitimidad de la mediación del poder político en estos asuntos. De esta manera, enfatizaba la urgencia de establecer un verdadero debate intelectual, basado en la prominencia de las ideas sobre el poder del Estado y la Iglesia. Mientras los argumentos de Calvo Serer coqueteaban abiertamente con los centros del poder político franquista (poco después de la publicación de España sin problema, Calvo Serer obtuvo el Premio Nacional de Ensayo "Francisco Franco»), Laín intentaba proponer un cierto distanciamiento respecto a los intereses oficiales y apoyarse en un poder propiamente intelectual. La heteronomía de los campos culturales de la postguerra y el dominio absoluto de los poderes políticos y eclesiásticos determinó el fracaso de la postura lainiana y el apoyo generalizado de la prensa, en especial del diario Arriba, a Calvo Serer. 


\section{Los indicios de crisis en la cultura del franquismo}

Hemos de tener en cuenta que, durante este periodo, la postura de Laín no formaba parte de un movimiento colectivo con cierto peso en el mundo de la cultura, sino que representaba una posición aislada, apoyada solamente por algunas personalidades como Dionisio Ridruejo. Otros mantenían un silencio revelador, como era el caso de Ortega y Gasset ${ }^{12}$. Durante el debate sobre el "problema de España» se cuestinó la versión oficial del franquismo, pero los apoyos a esta tenue rebeldía eran aún muy débiles y no contaban con ningún soporte institucional. A principios de los cincuenta, los sectores integristas del ámbito católico ejercían una influencia determinante en los campos culturales y científicos, imponiendo una visión espiritualista y escolástica del conocimiento poco afín al diálogo y al acercamiento comprensivo hacia formas alternativas de entender el mundo. Estos círculos rechazaban, sin establecer demasiados matices, las posiciones más laicas de oponentes como los falangistas heterodoxos o los discípulos de Ortega y Gasset. Sin embargo, pasado un tiempo, el movimiento iniciado por personajes como Laín o Ridruejo tuvo efectos relevantes y la hegemonía de la filosofía perenne empezó a ser contestada desde diversos sectores, no sólo fuera del catolicismo, sino también en su interior. El campo católico perdió su homogeneidad y la división entre los sectores conservadores y reformistas comenzó a reflejarse en las instituciones y los medios de comunicación.

En el sector conservador, surgió una renovación espiritual protagonizada por el Opus Dei, una asociación religiosa que afirmaba su neutralidad política y destacaba su vocación de servicio a la sociedad, basándose en la doctrina de la Tercera Fuerza. Diferenciándose de otras tendencias del catolicismo, el Opus Dei combinaba una concepción muy disciplinada de la experiencia religiosa con el fomento de la competitividad y la eficacia propias del capitalismo occidental ${ }^{13}$. Mediante la introducción de una visión del mundo de carácter tecnocrático y puritano, centrada en la racionalización y la planificación como motores de la acción humana, el Opus Dei participó activamente en el desarrollo y la modernización del capitalismo español. En los campos culturales, la influencia del Opus Dei también fue decisiva. Tomó el control de instituciones como el CSIC, la revista Arbor, el Ateneo de Madrid; creó la editorial Rialp y la Biblioteca de Pensamiento Actual. A través de estas plataformas culturales, difundió los valores del rigor, la disciplina y la competencia técnica, al mismo tiempo que evitaba cualquier aproximación crítica hacia el orden político establecido.

La regeneración del catolicismo conservador fue contestada por diversos movimientos heterodoxos desarrollados en el seno de la Iglesia. Las tendencias más progresistas intentaban reestablecer los vínculos entre el catolicismo, la tradición liberal española y las corrientes religiosas de otros países europeos.

12. Para ver una descripción del ambiente cultural de la época dominada por el catolicismo, ver Morán (1998, p. 214-59).

13. Gracia (1994, p. 86). 
Este sector encontró un órgano de expresión apropiado en la revista El Ciervo (1951), publicada en Barcelona e inicialmente dependiente de la organización católica $\mathrm{ACNP}^{14}$. El Ciervo se convirtió en la respuesta más exitosa a la problemática imparcialidad política del Opus Dei, al recobrar lo que entendían como el verdadero rol del intelectual católico en el mundo moderno. La publicación, dirigida por Lorenzo Gomis, tomó parte de su inspiración de la revista francesa Esprit, dirigida por el teólogo Emmanuel Mournier ${ }^{15}$. Las ideas de Esprit fueron muy influyentes en los sectores reformistas del catolicismo español, ya que sugerían nuevos caminos para reengancharse a las experiencias de la gente corriente, y ponerse así de nuevo al servicio de los pobres y desposeídos, como el cristianismo había hecho en sus orígenes más humildes. Para los representantes más atrevidos de esta postura, uno de los grandes escándalos del siglo XX era el cinismo mediante el cual la burguesía se había apropiado de los valores cristianos; por eso, aunque de forma muy ambigua y discreta al principio, El Ciervo se concibió como un proyecto para poner los valores del catolicismo al servicio de los débiles y los perdedores, es decir, de las clases trabajadoras ${ }^{16}$. En este contexto, la revista empezó uno de los debates más fructíferos que tuvo lugar entre la inteligencia antifranquista en las décadas siguientes: la discusión sobre la relación entre el catolicismo y el marxismo, donde personajes como Alfonso Carlos Comín tuvieron un papel muy importante. En otros casos, su incipiente cosmopolitismo y atención a la evolución de la cultura occidental facilitó el acercamiento entre el catolicismo y los falangistas más liberales, mediante la articulación de un catolicismo secular que huía de las posturas intransigentes del catolicismo más tradicional. La posición adoptada por uno de los colaboradores de la revista, el filósofo José Luis Aranguren, fue el resultado de esta fusión de horizontes religiosos y seculares.

La aparición de un núcleo renovador en el seno de la Iglesia católica tuvo también su reflejo en el ámbito académico. Efectivamente, los intelectuales que surgieron de los sectores progresistas del campo católico y falangista se convirtieron en maestros y en líderes políticos de los sectores más activos y concienciados de la población estudiantil. Contrastando con el arcaísmo de los neoescolásticos y su incapacidad para atraer a los jóvenes, los nuevos heterodoxos poseían una cantidad considerable de influencia y de poder simbóli$\mathrm{Co}^{17}$. El refuerzo simbólico de los enemigos ideológicos del franquismo estuvo acompañado por un movimiento inesperado en el campo político: la designación de Joaquín Ruiz-Giménez como ministro de Educación (1951-1956). Ruiz-Giménez representaba otra personalidad híbrida, situada entre el catoli-

14. Ver Gracia (1994, p. 88).

15. González Casanova (1992, p. 212).

16. González Casanova (1992, p. 223).

17. La crítica a la inanidad de la cultura oficial del franquismo ha sido expuesta por muchos autores. Utilizando una expresión que ha hecho fortuna, José Luis Abellán habla de un «verdadero páramo intelectual» (Abellán, 1971, p. 9). 
cismo y el falangismo, aunque en esos momentos aún era totalmente fiel al régimen franquista. A diferencia de sus antecesores, trabajó activamente para resolver las contradicciones existentes entre el campo franquista y el mundo de la cultura, siempre dentro de los límites de lo tolerable ${ }^{18}$. Para conseguir su objetivo, se rodeó de colaboradores con similares inclinaciones ideológicas. Dos figuras centrales del falangismo formaron el núcleo de su equipo: Laín Entralgo, como rector de la Universidad Complutense de Madrid, y Antonio Tovar, como rector de la Universidad de Salamanca. Bajo la mirada intranquila de las autoridades franquistas, el equipo de Ruiz-Giménez trabajó durante cinco años para revertir la lógica de los campos culturales, muy especialmente en el ámbito de la universidad. Su objetivo era acabar con la segregación de personas e ideas y volver a introducir una concepción más o menos ilustrada del conocimiento y la educación, sustentada en la idea del diálogo e intercambio de opiniones como método más fiable para alcanzar la verdad científica y humanística. El testigo de Ruiz-Giménez fue recogido por las generaciones de intelectuales más jóvenes, aquellos que no habían experimentado directamente la guerra civil, que llevaron las ansias de apertura mucho más lejos de lo que éste había pensado. Ellos serían los responsables de los incidentes universitarios de 1956 y de los primeros choques directos con el régimen ${ }^{19}$.

\section{La rebelión de los intelectuales jóvenes}

Los miembros de las nuevas generaciones universitarias expresaban sus ideas a través de los instrumentos de comunicación proporcionados por el movimiento falangista y por las autoridades académicas. Estos ambientes, estrechamente controlados por los poderes establecidos, eran lugares claramente inadecuados para lanzar debates intelectuales independientes, pero los estudiantes trataron de superar estas limitaciones enfrentándose simbólicamente contra quienes detentaban el poder académico. La fuerza de su argumentación residía en el deseo de introducir nuevos métodos analíticos y de aplicarlos al estudio de la realidad social. Estos grupos ayudaron a romper con el «tibetanismo» de la cultura española, introduciendo muchas de las ideas que circulaban por el resto de Europa. Si comparamos los contenidos de las revistas estudiantiles de este periodo con las de los miembros de la generación de 1936, el cambio generacional es muy evidente. Para la generacion del 36, el "problema de España» era un problema metafísico que requería una solución metafísica. Para los miembros de la naciente generación del 56, que escribían en diferentes medios controlados por el movimiento falangista, el «problema de

18. Díaz (1974, p. 62).

19. A partir de estos años, los estudiantes empezarán a ganar terreno en su lucha contra la Universidad del ancien régime, como la denomina Salvador Giner. Los estudiantes españoles empezaron a combatir por objetivos liberales «clásicos»: sindicatos libres, un sistema de educación moderno, el desarrollo de la ciencia y la investigación y la libre circulación de ideas (Giner, 1978, p. 322-3). 
España» era el resultado del fracaso del proceso modernizador del país. La solución no se encontraba en la metafísica, sino en el análisis científico de los problemas políticos y sociales ${ }^{20}$.

Éste era el caso, por ejemplo, de la revista Laye (1950-1953), fundada en Barcelona como un boletín cultural y destinada a los estudiantes de las diferentes universidades catalanas ${ }^{21}$. Desde el principio, Laye intentó facilitar la comunicación entre la jerarquía académica y el cuerpo de estudiantes, y aunque la revista mantenía un tono corporativo y didáctico, también incluía artículos técnicos y notas bibliográficas, así como textos sorprendentes escritos por jóvenes autores como Manuel Sacristán y Josep Maria Castellet, donde se trataba el problema de los intelectuales y su rol en la sociedad. Estos artículos marcarían el camino que seguiría Laye en un futuro inmediato. En 1951, después del undécimo número, el boletín se transformó en revista, al incrementar el número de páginas y adoptar una perspectiva mucho más analítica y crítica de la realidad académica. En sus páginas, encontramos una clara sensación de nostalgia por la atmósfera cultural que se había respirado en los años republicanos y, en especial, por proyectos editoriales como Revista de Occidente. En cierta medida, la revista de Ortega y Gasset aportó a los miembros de Laye un modelo cultural a imitar y en esa línea intentó, por una parte, formar una minoría ilustrada mediante la discusión de ideas complejas alejadas de los discursos oficiles y de la realidad cotidiana y, por otra, romper con el aislamiento cultural del país e introducir algunas de las novedades y los debates más importantes del pensamiento europeo contemporáneo ${ }^{22}$. Uno de los centros de atención de la revista era el trabajo de Martin Heidegger, que fue traducido y comentado detalladamente por Manuel Sacristán. Pero este proyecto intelectual se extendió con alusiones constantes al pensamiento de otros autores y herederos suyos como Jean-Paul Sartre. En uno de sus artículos, Sacristán llegó incluso a relacionar el trabajo de Heidegger con la filosofía racional e ilustrada de Kant. Así, mientras el Heidegger interpretado por los miembros de Escorial proporcionaba una interpretación conservadora de las relaciones sociales, el Heidegger de Laye, combinado con otras referencias intelectuales de vanguardia, proporcionaba una visión mucho más progresista y laica de la sociedad. Esta impresión se refuerza si tenemos en cuenta las conexiones internacionales de Laye con la revista de Sartre Les Temps Modernes, uno de los bastiones intelectuales de la izquierda en el periodo de la postguerra ${ }^{23}$. De todos modos, a pesar del apoyo de publicaciones con una reputación internacional como Les Temps Modernes, la autonomía cultural era prácticamente

20. Ver García San Miguel (1976, p. 166).

21. Para ilustrar los primeros titubeos del campo de las revistas políticas, en este artículo, debido a las restricciones evidentes del espacio, me voy a centrar en el análisis de tres publicaciones: Laye, Alcalá y Boletín Informativo. Sin embargo, también hubieron otras revistas que merecerían un espacio en un artículo más extenso, como Revista, Alférez o La Hora.

22. Riera (1988, p. 133-138).

23. Riera (1988, p. 136). 
imposible bajo el marco institucional que proporcionaba el movimiento falangista, y en 1953, después de una agresiva campaña de la prensa oficial y el Opus Dei, Laye fue finalmente clausurada.

El círculo de Castellet nos proporciona un ejemplo relevante de la aparición de una generación de jóvenes con nuevos intereses políticos y culturales, aunque también surgieron otras propuestas renovadoras de cierta importancia. En Madrid, encontramos una inciativa similar con la revista Alcalá (1952-1955), editada por el SEU. Pero si la comparamos con Laye, advertimos que era más ambigua en sus objetivos, y el poder político, a través de las autoridades académicas, se filtraba y se mezclaba más claramente en su contenido. En esta revista, la tradición liberal era aceptada como parte de su herencia, y muchos de sus miembros hicieron importantes esfuerzos para evitar la violencia simbólica del movimiento falangista y las visiones más estrictas y tradicionales de la Iglesia católica, pero también modificaron algunos de los elementos definidores del liberalismo para evitar esas regiones del pensamiento que pudieran ofender a los sectores más integristas de la universidad. Aspiraban a replantear el debate del "problema de España" superando la visión idealista de los miembros de Escorial, pero no disponían de las herramientas teóricas adecuadas para romper totalmente con esa tradición. Su perspectiva estaba compuesta por una complicada mezcla de empirismo y positivismo con restos de falangismo y de Ortega y Gasset. De todas maneras, a pesar del desaliño teórico, algunos artículos de Alcalá intentaron incorporar un marco analítico y sistemático para estudiar los temas sociales. La actitud protocientífica de algunos de sus colaboradores se unía a la defensa del reformismo católico y a un mensaje de solidaridad diseñado para combatir las injusticias sociales.

En contraste con los miembros de Laye, que rompieron de manera consciente con el tutelaje de la generación del 36, los componentes de Alcalá mantuvieron las conexiones con sus «hermanos mayores». La influencia de los maestros del 36 se puede observar en su aproximación liberal hacia el catolicismo, que conectaba con el trabajo de Laín y Tovar. Por otro lado, la rehabilitación de la racionalidad científica se basaba en las lecciones y las clases magistrales del filósofo Xavier Zubiri. Al final, todo este stock teórico se aplicó, entre otras cosas, para ayudar a la legitimación de las políticas académicas del ministro Ruiz-Giménez ${ }^{24}$.

Pero no todos los colaboradores de Alcalá apoyaban las acciones de RuizGiménez. En sus páginas, el sacerdote Fermín Yzurdiaga, antiguo director de la revista falangista Jerarquía, reprochaba la invasión de la cultura parisina y defendía de manera ferviente la superioridad del catolicismo ortodoxo sobre el existencialismo y lo que, según él, constituían las desafortunadas innovaciones del pensamiento francés. La sección más integrista de la revista se parapetaba detrás de la retórica de los ganadores y los perdedores de la guerra civil, 
que, desde su punto de vista, desvelaba las raíces de una España eterna ${ }^{25}$. De nuevo, las contradicciones en los mensajes internos de Alcalá pueden interpretarse como el resultado de la falta de autonomía de la revista en el campo académico. Las interferencias de poderes externos, manifestados en las imposiciones de las autoridades académicas y las influencias religiosas, rompió la cohesión y, en última instancia, la efectividad del mensaje de Alcalá.

Otra publicación de este periodo, cuyo impacto en el desarrollo del futuro campo de las revistas políticas es muy relevante, era Boletín Informativo del Seminario de Derecho Politico de la Universidad de Salamanca (1954-1964). Las características de esta revista eran diferentes a las de Laye o Alcalá. En contraste con éstas últimas, el contenido de Boletín Informativo lo decidía el consejo editorial, sin la interferencia de aparatos eclesiásticos o burocráticos, lo que le daba una autonomía que las otras publicaciones no tenían (no podía escapar, sin embargo, de la implacable censura externa). Boletín Informativo fue fundada por Enrique Tierno Galván, un filósofo de tendencia socialista vinculado cronológicamente con la generación del 36. La revista articuló un espacio de discusión para sus discípulos y otros investigadores sociales avanzados, muchos de ellos miembros de la generación de 1956 que más tarde formarían parte de la vanguardia teórica responsable de la recuperación del pensamiento socialista en España. Mientras Laye y Alcalá tendían a estar más interesados en la cultura alemana y francesa, Boletín Informativo se centró en los movimientos intelectuales anglosajones y, particularmente, en las posibilidades prácticas del positivismo lógico en España ${ }^{26}$. En su propio trabajo, Tierno Galván había identificado una «retórica de la oscuridad» en el pensamiento político y filosófico español, que, desde su punto de vista, conducían a la esterilidad intelectual y a la complacencia política. Su crítica al pensamiento metafísico está presente en el artículo "XII tesis sobre el Funcionalismo Europeo», publicado en Boletín Informativo en 1955, donde proponía un modelo de organización social y económico basado en la neutralidad política y en la eficiencia técnica. Con la aplicación de esquemas de pensamiento neopositivistas, Tierno Galván realizó una revolución simbólica de gran calibre dentro de un mundo cultural dominado todavía por el idealismo y otras formas de pensamiento metafísico, a lo que contribuyó también la traducción al castellano del Tractatus Logico-Philosophicus, de Wittgenstein, en 1957. El pensador madrileño, en compañía de sus discípulos, utilizó estos nuevos instrumentos teóricos para criticar la mentalidad acientífica de las prácticas culturales y políticas de la época. La introducción de una metodología científica en el ámbito académico, unida a los hábitos psicológicos y a las actitudes mentales tomadas del positivismo lógico, ayudaron a incrementar el rigor y la objetividad de la investigación social y el análisis político de los años siguientes ${ }^{27}$. Esta nueva corriente cultural se expandiría rápidamente por otros ámbitos sociales y, 
durante la década de 1960, fue muy influyente en los discursos elaborados en el campo político. El énfasis de Boletín Informativo en la objetividad científi$\mathrm{ca}$, aunque primeramente se aplicó a las metodologías de la investigación científica, pronto se uniría a sutiles demandas para el desarrollo de una lógica más racional y transparente en el campo político y la fortaleza franquista.

Laye, Alcalá y Boletín Informativo nos muestran cómo, durante los años cincuenta, una nueva generación de intelectuales intentó utilizar los espacios simbólicos proporcionados por las autoridades académicas para subvertirlos desde su interior, y así transformar el rígido orden simbólico de la universidad. Sus dificultades para ejercer alguna influencia demuestran cómo los discursos intelectuales no tienen poder por sí mismos; para ser eficaces, deben apoyarse en poderes culturales procedentes de campos relativamente autónomos. Algunos de los dispositivos de control del poder político, como el SEU, estaban en franca decadencia, pero tampoco existían los instrumentos ni las conexiones con el campo político necesarias para difundir las nuevas ideas al conjunto de la sociedad. Los dinamizadores de estas publicaciones estaban muy apartados de las fuentes del poder polìtico, y solamente podían contar con el apoyo de algunos profesores y catedráticos universitarios disidentes. A partir de ahora, se trabajará colectivamente en la creación de unas condiciones estructurales que faciliten el debate público, libre y sin restricciones, y la articulación de un verdadero espacio político. Esto supondrá, en cierto modo, escapar del exclusivismo de los foros universitarios.

\section{El mercado y la búsqueda de la autonomía}

Las publicaciones que acabamos de considerar circulaban dentro de grupos reducidos y tenían escasa repercusión fuera de los ambientes estrictamente académicos. Sin embargo, en los años sesenta, nos encontramos con un fenómeno nuevo: el desarrollo de un mercado cultural de masas. La extensión de la cultura de masas posibilitó el acceso de nuevos grupos sociales al consumo simbólico y, sin duda, ayudó a la creación de algo parecido a un espacio político. En realidad, hasta principios de los años sesenta no puede hablarse de la existencia de un espacio político en España, porque éste implica la existencia de diferentes alternativas ideológicas y la institucionalización de distintos partidos políticos con programas independientes. Las posiciones dispares en el debate sobre «el problema de España», por ejemplo, no pueden considerarse una demostración de pluralidad política, porque la relación de fuerzas estaba inclinada de manera apabullante hacia un lado de la balanza ${ }^{28}$.

28. Esta vision es incompatible con la «semioposición» y el «pluralismo limitado» que, según Juan Linz, caracterizaba al regimen franquista. El espacio político se fue creando en oposición al franquismo, gracias a la presion de diversos sectores sociales, y no desde dentro del franquismo. La diferentes familias orbitando alrededor de los centros de poder del régimen nunca llegaron a formar algo parecido a un espacio político, ni amplio ni restringido, ya que éste se caracteriza por la existencia de alternativas ideológicas reales y por la posibilidad 
El espacio político se fue abriendo lentamente, con todas sus limitaciones congénitas, gracias a la aportación de diferentes actores sociales, entre los que la intelectualidad desempeñó un papel muy importante. La inevitabilidad de este proceso llevó a la promulgación de la Ley de Prensa en 1966, mediante la cual se pretendía mantener su expansión bajo control. Los mecanismos de la censura se modificaron y se hicieron más flexibles para adaptarse a la realidad de un país que evolucionaba rápidamente hacia la modernidad económica y social. Aún así, la nueva ley era suficientemente ambigua (sobre todo en su segundo artículo) para permitir diferentes interpretaciones según las necesidades políticas del momento. Al final, aunque la Ley de Prensa era contradictoria en sus objetivos, en algunos aspectos facilitó el desarrollo de la producción cultural (y la conciencia crítica) y aceleró el «deshielo» de la sociedad española ${ }^{29}$.

A diferencia de los años cincuenta, en los cuales la amenaza disidente se difuminaba gracias al control burocrático sobre los campos de la cultura, en los años sesenta observamos, por primera vez desde la etapa republicana, la fundación de empresas culturales relativamente independientes (centros de investigación, editoriales, revistas) frente a los poderes establecidos ${ }^{30}$. Un caso muy iluminador fue el diario Madrid entre 1966 y 1971. Después de superar innumerables obstáculos burocráticos y desafiar directamente a los engranajes de la censura, durante algunos años el Madrid consiguió ocupar el centro del espacio político, compitiendo en el mercado con la prensa del régimen (Pueblo, $A B C$, La Vanguardia Española y algunos otros), claramente escorada hacia la derecha. Esta publicación estaba presidida por Rafael Calvo Serer, el antiguo contendiente de Pedro Laín Entralgo durante el enfrentamiento en torno al "problema de España». Sorprendentemente, Calvo Serer había evolucionado desde el integrismo católico hacia posiciones claramente liberales y democráticas ${ }^{31}$. Este movimiento hacia el centro de algunos sectores de la inteligencia tuvo serias repercusiones en la fortaleza franquista, al atacar suavemente, aunque de manera contundente, los soportes ideológicos más básicos del régimen. El Madrid pedía, por ejemplo, el reconocimiento del pluralismo político, exigía una transicion politica y el derecho a criticar y a exponer las limitaciones e incoherencias de las Leyes Fundamentales del Franquismo. Como podemos

de discutirlas públicamente. La competencia entre las familias del franquismo nunca fue pública; más bien dependía de intrigas palaciegas convenientemente ocultadas al resto de la sociedad. Ver Linz (1973, p. 171-259).

29. Otra expresion afortunada de Abellán, esta vez prestada de una imagen de Ridruejo. Adoptando la metáfora del "deshielo», Abellán se refiere a la progresiva apertura que se observa en el régimen, que cede a las presiones sociales, a partir de 1960 (Abellán, 1971, p. 36).

30. Creemos que el concepto de «autonomía relativa» es muy pertinente en este caso. La Ley de Prensa eliminó la censura previa, pero siempre existía la posibilidad de sanciones posteriores. Esto suponía una verdadera «espada de Damocles» para escritores y editores, que nunca estaban realmente seguros de si sus textos iban a ser sancionados o no. Ver Gubern (1981, p. 184-187).

31. Calvo Serer (1973, p. XXI). 
ver, sus propuestas iban más lejos que las tibias críticas metafísicas realizadas por Laín quince años atrás.

Pero, en la mayoría de los casos, el desarrollo de la oposicion intelectual al régimen y la colonización de nuevas regiones del espacio político (un movimiento que, inevitablemente, se dirigía hacia los territorios vírgenes de la izquierda) estuvo íntimamente unida al desarrollo de campos culturales que no funcionaban de acuerdo con la lógica de los campos más comerciales. El Madrid era la punta del iceberg de un movimiento de oposición política e intelectual que estaba organizándose en los sótanos del franquismo, y que tomaba su inspiración de diferentes versiones del marxismo. Las nuevas editoriales y revistas surgidas en estos años, conectadas entre ellas y relativamente autónomas respecto al poder político, se convirtieron en serias amenazas para el orden simbólico de la dictadura ${ }^{32}$. Estos mercados emergentes no poseían recursos políticos o económicos propios, pero empezaban a cultivar una nueva forma de poder simbólico, cimentada en el prestigio de los intelectuales entre los estudiantes y otros grupos contestatarios dentro de la sociedad franquista. Fue precisamente el desarrollo del mercado cultural de masas el que posibilitó la creación de estos mercados culturales paralelos, organizados en torno a la visión crítica y comprometida frente al régimen, porque éstos, aunque adoptaban algunas de las propiedades básicas del mercado, se separaban de su lógica general y su conformidad o indulgencia respecto al sistema político existente, para funcionar de acuerdo con principios e intereses muy diferentes.

En esta encrucijada histórica, en el cruce de caminos entre el desarrollo del mercado cultural y los primeros síntomas de agotamiento del régimen franquista, encontramos el momento crítico en el que surge el campo de las revistas políticas, y también, paralelamente, un poder intelectual con cierta efectividad política. La llegada de la autonomía, es decir, el momento en el cual la prensa especializada pudo actuar con cierta independencia y de acuerdo con sus propias normas, fue posible gracias a la introducción de nuevas fuerzas y poderes en el mundo de la cultura. La tradicional preponderancia del poder político y eclesiástico fue erosionada por la influencia creciente del poder económico (el desarrollo del mercado) y por la emergencia de un poder propiamente intelectual. Esta configuración específica de la libertad conllevó, como consecuencia inintencionada, el acercamiento generalizado del conocimiento a la lógica mercantil. La aceptación de la «mano invisible» del mercado suponía muchos riesgos relacionados con la precariedad de la autonomía intelectual y el riesgo de la trivialización cultural, pero también reveló nuevos canales a través de los cuales se podía influir en los discursos legitimadores del franquismo. En las próximas páginas, ilustraré la formación del campo de las revistas políticas, y la importancia que tuvo el mercado cultural en su génesis,

32. Según Elías Díaz, frente a la ocultación ideológica emprendida por el régimen franquista, estas publicaciones contribuyeron muy positivamente, por su significado crítico y su plural orientación democrática hacia una «reconstrucción de la razón» (Díaz, 1988, p. 202). 
tomando en consideración sus dos pilares más importantes: Cuadernos para el Diálogo y Triunfo ${ }^{33}$.

\section{Las condiciones políticas y económicas del diálogo}

En líneas generales, el campo de las revistas políticas fue el resultado del encuentro entre los sectores más progresistas de las esferas académicas y religiosas bajo las nuevas condiciones abiertas por el mercado cultural. Éste fue el caso de la revista Cuadernos para el Diálogo, creada en 1963 por el ex-ministro de Educación Joaquín Ruiz-Giménez. Después de su derrota política por los acontecimientos de 1956, Ruiz-Giménez regresó a su cátedra en la Universidad de Salamanca y, poco después, a la Universidad Complutense de Madrid. Retomó el trabajo académico y tuvo la habilidad de rodearse de un grupo de discípulos brillantes, como Gregorio Peces-Barba, Raúl Morodo o Elías Díaz, todos ellos miembros de la generación del 56. Al mismo tiempo, mantuvo las conexiones con los sectores más abiertos del campo católico. Durante estos años, en el seno de la Iglesia católica se desarrolló, bajo el papado de Juan XXIII y el Segundo Concilio Vaticano, un movimiento de renovación que siguió los cauces vislumbrados por revistas católicas progresistas como El Ciervo. Tomando en consideración el ensamblaje de campos sociales promovido por el franquismo, y el lugar hegemónico otorgado al campo eclesiástico dentro de esta jerarquía, no es de extrañar que la renovación del catolicismo promovida por el Vaticano tuviera implicaciones políticas muy importantes en España. RuizGiménez fue perfectamente consciente de ellas y, legitimado por las más altas jerarquías romanas, preparó su intervención en el campo político mediante la creación de Cuadernos para el Diálogo.

La revista apareció por primera vez en octubre de 1963 y sus objetivos fueron expuestos en el editorial del primer número. El proyecto político de RuizGiménez se articuló en torno a la idea del diálogo, entendido como el medio más adecuado para superar la división encarnizada entre los vencedores y los perdedores de la guerra civil. Cuadernos para el Diálogo se ofrecía a los lectores como una plataforma pública donde «facilitar la comunicación de ideas y sentimientos entre hombres de diferentes generaciones, creencias y actitudes vitales, en los asuntos más candentes del mundo social» ${ }^{34}$. Aunque al principio predominaban los cristianos y democristianos, la revista estaba abierta a un amplio espectro de visiones políticas, excluyendo sólo aquéllas que apoyaran la violencia o cualquier forma de discriminación. Este proyecto ambicioso de crear una estructura institucional estable y durarera, facilitadora del diálogo y

33. Cuadernos para el Diálogo y Triunfo eran, sin duda, las publicaciones más representativas del campo de las revistas políticas bajo el franquismo (ver Ysàs, 2004, p. 65) pero habían muchas más. Sin ánimo exhaustivo, ya que no es ésta la pretension del artículo, citaremos algunas de ellas: la recuperación de Revista de Occidente, Praxis, Realidad, El Ciervo, Serra d'Or, Cuadernos de Ruedo Ibérico e Índice.

34. Díaz (1983, p. 114). 
la comunicación sin distorsiones, fue muy bien acogida por amplios sectores de la comunidad intelectual española. Bien es cierto que el apoyo más directo surgió de los compañeros generacionales de Ruiz-Giménez, hombres como Laín Entralgo, Tovar, Aranguren o Tierno Galván, y también de los representantes de los movimientos más abiertos dentro del catolicismo ${ }^{35}$. No obstante, en otros casos, como era el de Ridruejo, aunque fueran críticos con las bases idealistas que sustentaban el proyecto, colaboraron cuando fueron requeridos por la revista.

Una diferencia fundamental entre el instrumento de comunicación e intervención política creado por Ruiz-Giménez y las revistas estudiadas anteriormente es que, mientras éstas dependían de estructuras de poder político externas, Cuadernos consiguió evitar dicha relación de subordinación asentándose plenamente en el mercado. Al situarse en este contexto, no dependía de ninguna burocracia pública o institución cultural más o menos oficial. Por tanto, la independencia respecto a los poderes políticos la consiguió mediante su transformación en una empresa económica en constante competición con otras publicaciones para captar lectores y suscriptores, y asumiendo la necesidad imperante de conseguir un margen mínimo de beneficios. La publicación alcanzó, en su momento más álgido, una tirada de 120.000 ejemplares, en contraste con los escasos centenares de ejemplares que tiraban las revistas anteriores. De todas formas, como ya hemos sugerido, la configuración de la libertad concebida por los miembros de Cuadernos, la aceptación de las reglas del mercado, conllevaba otras formas de sumisión que resultaban difíciles de gestionar de manera adecuada. Al final, Cuadernos siempre permaneció en una posición de debilidad frente a los requerimientos del mercado y la cultura de masas. Su singular inversión de la lógica económica, la preferencia del poder simbólico e intelectual sobre el poder político y económico, imposibilitó la obtención de un balance de cuentas satisfactorio, lo que interfirió gravemente en su consolidación institucional ${ }^{36}$.

Hemos de tener en cuenta que el proyecto intelectual de Cuadernos para el Diálogo comprendía, no sólo una revista de difusión mensual, sino también una editorial con una larga lista de títulos publicados. Los dos primeros libros editados, Moral y Sociedad, de Aranguren, y Estado de Derecho y Sociedad Democrática, de Elías Díaz, definen claramente el espíritu de esta empresa intelectual. Aquí nos encontramos, por un lado, con la contribución de la generación del 36, representada por Aranguren. Este grupo de intelectuales estaba firmemente establecido en los diferentes campos culturales, tenían un stock significativo de poder simbólico y una considerable influencia en el campo político. Formados en un ambiente caracterizado por el rechazo del positivismo, su aproximación al análisis de los asuntos sociales se basaba en disciplinas como la ética o la filosofía. El interés de Aranguren por la moral enlaza 
con los temas y las cuestiones teóricas propuestas por Escorial en los años cuarenta. Pero, por otra parte, encontramos también la aportación de los jóvenes miembros de la generación de 1956, como Elías Díaz, que introdujeron una aproximación científica y empírica a la investigación social y, utilizando las herramientas del conocimiento científico, pretendieron desvelar el carácter ideológico de la realidad oficial ${ }^{37}$.

Aunque ambas generaciones partían desde orígenes ideológicos diferentes, su aproximación coincidía en el objetivo básico: emprender la colonización del centro y el centro-izquierda del espacio político y hacer una llamada clara para avanzar hacia una democracia política. De esta manera, el sistema democrático promovido por Cuadernos oscilaba entre la socialdemocracia, tal como era entendida en los países occidentales más avanzados, y el socialismo democrático, que intentaba llevar el proyecto de reforma social un poco más lejos, asumiento algunas de las críticas del marxismo a la socialdemocracia.

\section{La revolución política y la seducción de la cultura de masas}

El otro pilar institucional que sustentaba el campo de las revistas políticas era el semanal Triunfo. Esta publicacion compartía con Cuadernos para el Diálogo una lógica de funcionamiento contradictoria y difusa, donde se intentaban conciliar las necesidades del mercado económico con los intereses y las obligaciones de un proyecto político e intelectual. Triunfo comenzó su andadura en 1946 como una revista dedicada a la crítica de cine. La revista mantuvo un buen índice de ventas durante la década de los cincuenta y, a principios de los sesenta, el poderoso grupo de comunicación Movierecord se interesó por sus posibilidades empresariales. El director de Triunfo, José Ángel Ezcurra, aceptó la oferta de Movierecord y desarrolló un plan mucho más ambicioso para la nueva época de la publicación siguiendo modelos internacionales como Paris Match, basados en la presentación de una estética impactante mediante la profusión del color y la fotografía, el diseño de primeras páginas atractivas y una aproximación sencilla y clara a los temas tratados ${ }^{38}$. Los cambios en la forma fueron acompañados por cambios en el contenido, con una atención mayor hacia otros fenómenos culturales, más allá del tradicional interés por el cine, como la literatura, el arte y la filosofía. Lo más interesante de Triunfo en su nueva etapa es que, bajo la fachada de un producto mediático destinado al consumo de masas y al entretenimiento cultural, se vislumbra, casi desde el principio, un intento consciente de escrutar las acciones del poder político. Esta intención implícita se acentuó a medida que pasaron los años, gracias al apoyo de Ezcurra y del consejo editorial, aunque no siempre de Movierecord. Fue precisamente esta combinación entre la difusión de la cultura pop y el análisis político más riguroso lo que definió la arriesgada toma de posición empren- 
dida por Triunfo dentro del campo de las revistas políticas, compitiendo al mismo tiempo con revistas ligeras y revistas políticas especializadas. El primer número de la nueva época apareció en 1962 y alcanzó una circulación de 57.000 ejemplares, que, con el tiempo, se elevarían hasta los 160.000. A partir de este momento, intelectuales con cierto renombre, y otros que alcanzarían el reconocimiento muy pronto, se unieron al proyecto, como Eduardo Haro Tecglen, Enrique Miret Magdalena y Manuel Vázquez Montalbán. Estos autores proporcionaron a Triunfo la suficiente legitimidad intelectual para participar en el debate intelectual y criticar a los conceptos centrales que definían a los discursos políticos de la época, con lo que se ampliaban los límites del espectro político de la izquierda.

Aunque, en este punto, Triunfo disfrutaba de un cierto espacio de maniobra frente a las presiones de los poderes políticos y económicos, en último término su autonomía era muy limitada. Utilizando la tradicional terminología marxista, la fuerza del trabajo intelectual no estaba acompañada por la propiedad de los instrumentos para la producción intelectual. Las cosas cambiaron después de la bancarrota de Movierecord en 1969, cuando el consejo editorial tuvo la oportunidad de hacerse con el control de la revista. Bajo estas nuevas circunstancias, el consejo fue capaz de definir el contenido de la revista sin presiones externas, priorizando un compromiso colectivo centrado en la defensa de la libertad intelectual frente a los poderes políticos y económicos. De un modo similar al de Cuadernos, Triunfo expandió el abanico de actividades creando Hermano Lobo, una revista humorística pero con un mensaje político innegable, y Tiempo de Historia, una revista académica dirigida por Eduardo Haro Tecglen y orientada hacia la recuperación de aquellas partes de la historia española censuradas y borradas por la historiografía franquista.

La relación contradictoria entre las racionalidades que definen el mercado y la cultura, evidente en Cuadernos para el Diálogo, era aún más aguda en Triunfo. Cuadernos aceptaba las reglas esenciales del mercado, las molestias impuestas por las necesidades mercantiles eran entendidas como una consecuencia inevitable de la búsqueda de la autonomía intelectual, aunque, en último término, rechazaba su plena integración en el campo económico. Su estilo se caracterizaba por la austeridad académica, la seriedad y la precisión, como manera de enfatizar la seriedad y la dignidad última de la revista. En contrastre, Triunfo seguía las pautas del mercado de manera mucho más directa, adaptándose a las demandas de la economía del entretenimiento y aceptando sus consecuencias, aunque, paradójicamente, presentaba un mensaje mucho más revolucionario que Cuadernos, una intención que iba más allá de la superación del franquismo y que pretendía tambien transformar el sistema capitalista en su totalidad.

En terminos políticos, Triunfo se situaba en la izquierda y en la extrema izquierda del espacio político, incluso en ciertos momentos abrazaba posturas claramente libertarias y revolucionarias. El radicalismo de Triunfo estaba íntimamente ligado a la aparición de una nueva generación de intelectuales que había desarrollado una visión del mundo diferente a la de sus padres del 56 y 
sus abuelos del 36. Como hicieran las generaciones anteriores en distinto grado y medida, los miembros del 68 se rebelaban contra la autoridad y legitimidad del franquismo, pero también, y en esto divergían especialmente del 56, contra la democracia liberal burguesa, el Estado de bienestar y las alternativas comunistas al capitalismo. Es más, reaccionaban contra la mentalidad científica y empírica introducida por la generación del 56, en consonancia con los movimientos contraculturales de otras zonas del planeta, reintroduciendo en el espacio intelectual elementos de irracionalidad procedentes de las más variadas tradiciones occidentales y orientales ${ }^{39}$. Sin embargo, la revista de Ezcurra no era un órgano exclusivo de la generación del 68; la generación del 56 también estaba presente, con nombres tan reconocidos como Eduardo Haro Tecglen y Enrique Miret Magdalena.

En este sentido, la tensión entre el 56 y el 68 se puede observar contrastando los artículos que escribían algunos de sus representantes, como Eduardo Haro Tecglen, representante de la primera, y Manuel Vázquez Montalbán, miembro de la segunda. Los artículos de Haro Tecglen proporcionaban a los lectores de Triunfo análisis precisos y bien documentados sobre asuntos políticos de carácter internacional, que muchas veces eran referencias veladas a la situación política interna. Del mismo modo que otros miembros de su generación, como hemos visto en Elías Díaz, utilizaba las herramientas del conocimiento científico, en este caso de la ciencia política, para revelar el funcionamiento interno del franquismo y la irracionalidad inherente del sistema. La crítica de Vázquez Montalbán, por otro lado, era bastante diferente, porque atacaba la irracionalidad del campo político franquista desde una atalaya intelectual directamente influenciada por otras formas de conocimiento críticas con el racionalismo y el elitismo occidental. En sus artículos, por ejemplo, comparaba la sociedad neocapitalista con la Capilla Sixtina de Miguel Ángel, enfatizando así la confusión y el carácter apocalíptico de las sociedades modernas ${ }^{40}$. Utilizaba imágenes de ángeles y santos, demonios y asesinos, para dar sentido a un mundo en el que el rol de los intelectuales, y la misma función de la política, estaba abiertamente en entredicho.

\section{Sobre los usos más adecuados del poder intelectual}

El campo de las revistas políticas surgido a finales del franquismo ayudó, por tanto, a establecer unas condiciones institucionales adecuadas para el desarrollo del poder intelectual como una fuerza con cierto peso social. El poder político (y también el eclesiástico) se había retirado parcialmente de algunos campos culturales, y los poderes intelectuales y económicos ocuparon su lugar. En consecuencia, estas regiones adquirieron una mayor autonomía para gobernarse de acuerdo con las reglas del conocimiento científico y los principios 
(aparentemente amistosos e inocuos) del mercado. Dos décadas después del enfrentamiento entre Laín Entralgo y Calvo Serer sobre la cuestión del "problema de España", el poder intelectual no era un ideal abstracto (como lo había sido en el caso de la postura adoptada por Laín), sino una realidad con un cierto grado de institucionalización.

De todas formas, bajo las nuevas condiciones establecidas para el desarrollo de la práctica cultural, algunas voces comenzaron a criticar la concentración del poder intelectual en manos de unos pocos y su utilización frívola e inadecuada para defender determinados intereses particulares, con lo que se destruía su naturaleza crítica y emancipadora. Los enfrentamientos sobre los usos del poder intelectual empezaron en 1965, cuando el autor teatral madrileño Alfonso Sastre publicó un artículo en Cuadernos para el Diálogo sobre lo que llamó los «inspectores privados de la cultura», seguido de su libro La revolución y la crítica de la cultura (1970). En esta obra, Sastre atacaba el mercantilismo de la vida intelectual española y la creación y destrucción de reputaciones intelectuales mediante procedimientos extraños al mundo de la cultura. Observaba que la influencia de la política en la cultura era menos dañina que las nuevas formas de poder originadas en los pliegues de los propios campos culturales. En este punto, el objetivo de su ataque no era el poder de la crítica, es decir, la capacidad legítima de determinados agentes culturales para comentar, criticar y clasificar públicamente autores y obras dependiendo de un conjunto de criterios preestablecidos. Su ira se dirigía hacia los críticos privados que poseían una autoridad objetiva que no había sido conferida por la autoridad legítima del campo cultural. Estos administradores ilegítimos pululaban en los márgenes de las instituciones culturales más importantes, en los filtros donde se seleccionaban y se difundían los productos culturales (editoriales, revistas, cenáculos literarios), actuando como grupos de presión defensores de intereses particulares ${ }^{41}$. La crítica de Sastre estaba dirigida específicamente al triángulo catalán formado por el crítico literario Josep Maria Castellet, el editor Carlos Barral y el escritor Juan Goytisolo, que se estaban alejando rápidamente del compromiso político de la década de 1950 y primeros años de la de 1960.

Desde los días de Laye, Castellet había tenido una importancia crucial en la organización de los primeros círculos de disidencia intelectual en Barcelona y en la introducción de nuevos movimientos filosóficos y literarios, como el existencialismo de Sartre y la literatura del compromiso. Durante los años sesenta, Castellet y los suyos evolucionaron hacia posiciones intelectuales completamente diferentes, rechazando las ideas de Sartre sobre el compromiso político en favor del arte por el arte y de la autonomía total del universo cultural, sin ningún tipo de intención social o política ulterior. En círculos periodísticos, los integrantes de estos grupos fueron denominados la gauche divine, en referencia a la interpretación bohemia que hacían de la cultura de izquierdas. En 
1970, Triunfo publicó la carta de un misterioso Luis, muy probablemente un pseudónimo del propio Sastre, en donde se atacaba el «imperialismo de la cultura catalana», refiriéndose obviamente al grupo de Castellet y su supuesto apoyo a la frivolidad cultural y a la complacencia política. En opinión de Luis, la aparición de la gauche divine y otros grupos relacionados con ellos estaba vinculada al desarrollo del capitalismo catalán y a sus estructuras de dominación política y económica. Aunque estos grupos no actuaban como extensiones del poder político (ya que poseían sus propias formas de poder intelectual), él consideraba que la vacuidad de su aproximación a la creación cultural facilitaba la reproducción del capitalismo del mismo modo que lo haría una sumisión total. Estos grupos mantenían conexiones con editoriales y revistas específicas como Anagrama, Seix y Barral, Lumen, Edicions 62 (y, unos pocos años después, Ajoblanco), y también tenían enlaces con Madrid a través de Triunfo e Informaciones, mediante los cuales, según Sastre, se difundían todos estos productos simbólicos que traicionaban el legado emancipador de la izquierda ${ }^{42}$.

La respuesta a la carta de Luis fue publicada inmediatamente en las páginas de Triunfo por algunos intelectuales vinculados a la gauche divine y a los círculos más progresistas de la inteligencia barcelonesa, como el filósofo Eugenio Trías. En su respuesta a las críticas de Luis, Trías defendía la introducción de las corrientes irracionalistas del pensamiento europeo contemporáneo y citaba como ejemplos el pensamiento de Artaud, Nietzsche y Sade. Estos autores, según él, habían llevado a cabo la crítica más severa y la subversión más radical de la cultura moderna, al atacar los cimientos que sostenían sus instituciones y valores. Según Trías, la acusación de irracionalidad, e incluso de fascismo objetivo, lanzada por Sastre era una estrategia banal destinada a defender el statu quo existente y los esquemas de pensamiento político heredados del pasado, eludiendo cualquier compromiso crítico con ellos ${ }^{43}$. En contraste con Sastre, Trías pretendía separar claramente las funciones del político y del intelectual en la sociedad moderna. Así, mientras atacaba la visión marxista del intelectual comprometido, defendía al mismo tiempo una autonomía total del intelectual, que debía expresarse mediante prácticas festivas como las de los carnavales. Siendo un miembro del 56 profundamente comprometido con la lucha de clases, Sastre no podía aceptar los valores carnavalescos otorgados por Trías a los productores culturales. Pretendía, por el contrario, recuperar la pureza revolucionaria de antaño, la disciplina y el rigor frente a los enemigos declarados del socialismo. En ese mismo año, ante el comité central del partido comunista, del que era miembro, Sastre mostró su fascinación por el grupo terrorista ETA y por sus violentos métodos de acción política. En los años siguientes, su determinación revolucionaria lo llevarían a los brazos del nacionalismo vasco más radical y al extremo del arco ideológico. 
El enfrentamiento entre Sastre y Trías muestra como, en tan sólo un par de décadas, se pasó de la crítica aislada al desarrollo de contextos sociales en los cuales se podían discutir ideas diversas con unos mínimos de seguridad e independencia, siempre bajo la mirada acechante de la censura ${ }^{44}$. A pesar de las limitaciones, es indudable que las condiciones para el debate público habían mejorado y los productores culturales habían desarrollado sus propios recursos materiales y simbólicos para contrarrestar los obstáculos impuestos por las autoridades políticas. Aunque el poder político aún circulaba en los campos culturales especializados (y la influencia, muchas veces opresiva, de los partidos políticos de la oposición al franquismo, en especial el PCE, era muy importante), los instrumentos y los mecanismos necesarios para defenderse estaban disponibles en el mercado de la producción simbólica. El campo de las revistas políticas alcanzaría su plenitud en los primeros años de la transición, gracias a la labor de los viejos estandartes de la oposición al franquismo (Triunfo y Cuadernos para el Diálogo) y la nueva generación de revistas nacidas a su sombra (El Viejo Topo, Argumentos, Sistema y Materiales, entre otras muchas). Sin embargo, paradójicamente, el momento culminante fue también el comienzo de un rápido declive, y la mayor parte de estas publicaciones desaparecerían en los años siguientes. Su influencia se haría notar en otros ámbitos de la cultura, especialmente en la renovación del mundo periodístico y en la aparición de empresas editoriales como el diario El Pais.

En conclusión, en este artículo hemos delineado, de manera necesariamente concisa, la aparición y desarrollo del campo de las revistas políticas en la España franquista, un lugar donde se abrieron nuevos espacios para el debate y se desarrollaron visiones críticas sobre la situación política y social del país. Su génesis y su supervivencia fue posible por la reorganización de las relaciones de poder dentro del mundo cultural del tardofranquismo, con la retirada parcial de algunos poderes (el polìtico y el eclesiástico) y el protagonismo creciente de otros (el económico y el intelectual). Así, el campo de las revistas políticas se convirtió en una de las fuentes de alimentación básicas que posibilitó la existencia del poder intelectual, un poder procedente del mundo cultural y con una cierta independencia frente al resto de las fuerzas sociales tradicionales. El nuevo poder intelectual propiciado por estas publicaciones no solamente aseguró cierta independencia para determinados productores culturales, sino que, gracias a su prestigio en diferentes ámbitos sociales, facilitó también su participación pública en el debate político.

44. Esta independencia no era completa y algunas revistas tenían que publicarse en el exterior, como Cuadernos de Ruedo Ibérico o Realidad (Díaz, 1988, p. 203). 


\section{Bibliografía}

ABELlán, J.L. (1974). La cultura en España (ensayo para un diagnóstico). Madrid: Cuadernos para el Diálogo.

- (1978). Panorama de la filosofía española actual: Una situación escandalosa. Madrid: Espasa-Calpe.

Altares, P. (1997). «La historia de Cuadernos para el Diálogo». En: La fuerza del Diálogo: Homenaje a Joaquín Ruiz-Giménez. Madrid: Alianza.

Alted, A. (ed.) (1992). Triunfo en su época. Madrid: Ediciones de la Pléyade.

BIESCAS, J.A.; TUÑÓN DE LARA, M. (1980). España bajo la dictadura franquista (19391975). Barcelona: Labor.

Bourdieu, P.; WaCQUANT, P. (1992). An invitation to reflexive sociology. Cambridge: Polity Press.

CAlVO SERER, R. (1973). La dictadura de los franquistas. El «affaire» del Madrid y el futuro político. París: Ruedo Ibérico.

DíaZ, E. (1983). Pensamiento español en la era de Franco. Madrid: Tecnos.

- (1990). Ética contra politica: los intelectuales y el poder. Madrid: CEC.

EzCuRRA, J. (1995). «La historia de Triunfo». En: Alted, A.; AuBERT, P. (eds.). Triunfo en su época. Madrid: Casa de Velázquez-Las Pléyades.

FusI, J.P. (1999). Un siglo de España: la cultura. Madrid: Marcial Pons.

GARCÍA-VELASCO, J. (1997). "Cuadernos en la tradición universitaria institucionista». En: La fuerza para el Diálogo: homenaje a Joaquín Ruiz-Giménez. Madrid: Alianza.

GINER, S. (1978). «Libertad y poder político en la universidad española: el movimiento democrático bajo el franquismo». En: PRESTON, P. (ed.). España en crisis: evolución y decadencia del régimen de Franco. Madrid: FCE.

González Casanova, J.A. (ed.) (1992). La revista El Ciervo. Barcelona: Península.

Gracia, J. (1994). Crónica de una deserción. Ideología y literatura en la prensa universitaria del franquismo (1940-1962). Tolosa: Presses Universitaires du Mirail.

- (1996). Estado y cultura: El despertar de una conciencia crítica bajo el franquismo. Barcelona: Ediciones Península.

- (2004). La resistencia silenciosa: fascismo y cultura en España. Barcelona: Anagrama.

GUBERN, R. (1981). La censura: función politica y ordenamiento jurídico bajo el franquismo (1936-1975). Barcelona: Península.

Juliá, S. (2004). Historias de las dos Españas. Madrid: Taurus.

LiNZ, J.J. (1973). «El régimen autoritario: el caso de España». En: DAHL, R.A. (ed.). Regimes and Oppositions. New Haven y Londres: Yale University Press.

LizCano, P. (1981). La generación del 56: La universidad contra Franco. Barcelona: Grijalbo.

MAINER, J.C.; JULIÁ, S. (2000). El aprendizaje de la libertad. Madrid: Alianza.

MANGINI, S. (1987). Rojos y rebeldes: La cultura de la disidencia durante el franquismo. Barcelona: Anthropos.

MARTíneZ, J.; GÓMEZ NAVARRO, J. (1997). «Reflexiones empresariales». En: La fuerza del diálogo: Homenaje a Joaquín Ruiz-Giménez. Madrid: Alianza.

MeSA, R. (ed.) (1982). Jaraneros y alborotadores: Documentos sobre los sucesos estudiantiles de febrero de 1956 en la Universidad Complutense de Madrid. Madrid: Ediciones de la Universidad Complutense.

MorÁn, G. (1998). El maestro en el erial: Ortega y Gasset y la cultura del franquismo. Barcelona: Tusquets. 
PLATA, G. (1999). La razón romántica: la cultura política del progresismo español a través de Triunfo (1962-1975). Madrid: Biblioteca Nueva.

RierA, C. (1988). La escuela de Barcelona. Barcelona: Anagrama.

SASTRE, A. (1970). La revolución y la crítica de la cultura. Barcelona: Grijalbo.

VV.AA. (1997). La fuerza del diálogo: homenaje a Joaquín Ruiz-Giménez. Madrid: Alianza Editorial.

YSÀS, P. (2004). Disidencia y subversión: La lucha del régimen de franquista por su supervivencia, 1960-1975. Barcelona: Crítica. 